\title{
Methotrexate-loaded lipid-core nanocapsules are highly effective in the control of inflammation in synovial cells and a chronic arthritis model
}

This article was published in the following Dove Press journal:

International Journal of Nanomedicine

22 October 2015

Number of times this article has been viewed

\author{
Antônio Luiz Boechat ${ }^{1,2, *}$ \\ Catiúscia Padilha de \\ Oliveira ${ }^{3, *}$ \\ Andrea Monteiro Tarragô ${ }^{2}$ \\ Allyson Guimarães da \\ Costa ${ }^{2}$ \\ Adriana Malheiro ${ }^{1,2}$ \\ Silvia Stanisçuaski \\ Guterres $^{3}$ \\ Adriana Raffin Pohlmann ${ }^{3,4}$ \\ 'Departamento de Parasitologia, \\ Instituto de Ciências Biológicas, \\ Universidade Federal do Amazonas, \\ Manaus, ${ }^{2}$ Programa de Pós-Graduação \\ e Imunologia Básica e Aplicada, \\ Universidade Federal do Amazonas, \\ Manaus, ${ }^{3}$ Programa de Pós-Graduação \\ em Ciências Farmacêuticas, Faculdade \\ de Farmácia, ${ }^{4}$ Departamento de \\ Química Orgânica, Instituto de \\ Química, Universidade Federal do Rio \\ Grande do Sul, Porto Alegre, Brazil \\ *These authors contributed equally \\ to this work
}

Correspondence: Adriana Raffin Pohlmann Departamento de Química Orgânica, Instituto de Química, Universidade Federal do Rio Grande do Sul, Av Bento Gonçalves 9500, PO Box I5003, CEP 9150 I-970, Porto Alegre, RS, Brazil Tel +55 5I 33087237

Email adriana.pohlmann@ufrgs.br

Antônio Luiz Boechat

Departamento de Parasitologia, Instituto de Ciências Biológicas, Universidade Federal do Amazonas, Av General Rodrigo Otávio, 3000 - Coroado I, CEP 69077-000, Manaus, AM, Brazil $\mathrm{Tel}+559281273388$

Email alboechat@ufam.edu.br
Background: Rheumatoid arthritis (RA) is the most common autoimmune disease in the word, affecting $1 \%$ of the population. Long-term prognosis in RA was greatly improved following the introduction of highly effective medications such as methotrexate (MTX). Despite the importance of this drug in RA, $8 \%-16 \%$ of patients must discontinue the treatment because of adverse effects. Last decade, we developed a promising new nanocarrier as a drug-delivery system, lipid-core nanocapsules.

Objective: The aim of the investigation reported here was to evaluate if methotrexate-loaded lipid-core nanocapsules (MTX-LNC) reduce proinflammatory and T-cell-derived cytokines in activated mononuclear cells derived from RA patients and even in functional MTX-resistant conditions. We also aimed to find out if MTX-LNC would reduce inflammation in experimentally inflammatory arthritis at lower doses than MTX solution.

Methods: Formulations were prepared by self-assembling methodology. The adjuvant arthritis was induced in Lewis rats (AIA) and the effect on edema formation, TNF- $\alpha$ levels, and interleukin-1 beta levels after treatment was evaluated. Mononuclear cells obtained from the synovial fluid of RA patients during articular infiltration procedures were treated with MTX solution and MTX-LNC. For in vitro experiments, the same dose of MTX was used in comparing MTX and MTX-LNC, while the dose of MTX in the MTX-LNC was 75\% lower than the drug in solution in in vivo experiments.

Results: Formulations presented nanometric and unimodal size distribution profiles, with $\mathrm{D}[4.3]$ of $175 \pm 17 \mathrm{~nm}$ and span of 1.6 \pm 0.2 . Experimental results showed that MTX-LNC had the same effect as MTX on arthritis inhibition on day 28 of the experiment $(P<0.0001)$; however, this effect was achieved earlier, on day $21(P<0.0001)$, by MTX-LNC, and this formulation had reduced both TNF- $\alpha(P=0.001)$ and IL-1 $\alpha(P=0.0002)$ serum levels by the last day of the experiment. Further, the MTX-LNC were more effective at reducing the cytokine production from mononuclear synovial cells than MTX.

Conclusion: The MTX-LNC were better than the MTX solution at reducing proinflammatory cytokines and T-cell-derived cytokines such as interferon-gamma and interleukin-17A. This result, combined with the reduction in the dose required for therapy, shows that MTX-LNC are a very promising system for the treatment of RA.

Keywords: drug delivery, drug targeting, arthritis, cytokines, TNF- $\alpha$, IL-6, IL-1, IL-17A, IFN- $\gamma$

\section{Introduction}

Rheumatoid arthritis (RA) is the most common autoimmune disease, and it affects $1 \%$ of the world's population. ${ }^{1}$ The disease affects the synovial membrane of joints, and, if not properly treated, leads to joint destruction and disability, loss of work 
productivity, and poor quality of life. ${ }^{2}$ Moreover, RA is associated with a high prevalence of comorbidities, such as cardiovascular diseases, in affected individuals. ${ }^{3}$ Notably, a reduced life expectancy in RA sufferers compared with the normal population has been reported. ${ }^{4}$ Although the exact immunological mechanism for the disease etiology remains unclear, both genetic background and environmental factors have been associated with the loss of tolerance and rising autoimmunity. ${ }^{5,6}$ It should be emphasized that RA involves high costs of treatment regarding medications (especially biologics), surgical procedures, and indirect costs. ${ }^{7}$ Thus, it is clear that optimized treatments are required to minimize the clinical and socioeconomic impacts of RA.

In the previous decade, the long-term prognosis of RA greatly improved following the introduction of highly effective medications, such as methotrexate (MTX) and biologic agents, as well as treatment adjusted to target low disease activity or remission. ${ }^{3}$ MTX is the cornerstone of RA and other rheumatic disease treatments. MTX was first developed in the 1940s as a specific antagonist of folic acid that inhibits the proliferation of malignant cells. ${ }^{8}$ However, the demonstration in 1985 that intermittent low-dose MTX is a potent and effective therapy for RA dramatically changed the main concepts of patient treatment. ${ }^{9}$ At least two different mechanisms are responsible for the anti-inflammatory properties of MTX. Regardless of MTX's pharmacodynamics, MTX treatment can reduce cytokine levels and synovial and systemic inflammation. ${ }^{10,11}$

Despite the importance of MTX for RA and other inflammatory conditions, it should be noted that $8 \%-16 \%$ of patients must discontinue the drug because of adverse effects, such as hepatic, gastrointestinal, hematological, renal, and pulmonary problems. ${ }^{12}$ The clinical responsiveness of RA patients to MTX treatment is another important issue. Approximately $26 \%$ of patients treated with MTX must stop the drug because of poor response, high toxicity, or both. ${ }^{13}$ Accordingly, the intra-articular administration of MTX was tested, but the results were not fully successful because of the rapid clearance of MTX from the joints. ${ }^{14}$

Many different nanocarriers, which are used as drugdelivery systems, have the potential to achieve the treatment goals of rheumatic conditions. ${ }^{15,16}$ Diverse approaches have been tested to overcome the discussed issues and to concentrate MTX at inflammatory sites. ${ }^{16}$ In this line of investigation, it is well known that the intravenously administered nanoparticles over $100 \mathrm{~nm}$ can concentrate mainly at inflammatory sites because of their particle size, which enables the nanocarriers to only cross defective capillary vessels, thereby avoiding the liver, spleen, and bone marrow. ${ }^{17}$ These findings could maximize the therapeutic index to reduce adverse effects and improve drug benefits.

In the previous decade, we developed a new system that contains an organogel core, which is formed by a dispersion of sorbitan monostearate in medium-chain triglycerides, surrounded by a polymeric wall of poly( $\varepsilon$-caprolactone) (PCL) and stabilized by polysorbate 80 micelles. ${ }^{18-21}$ This new nanoparticulate system is referred to as lipid-core nanocapsules (LNC), and it has proved an interesting nanocarrier for indomethacin for the therapy of glioblastomas and the inflammation process, ${ }^{22,23}$ as well as for methotrexate diethyl ester and tretinoin, which have been implicated in the reversion of tumor resistance. ${ }^{24,25}$ Based on the promising properties of LNC as a new drug-delivery system, the aims of our investigations were to evaluate whether methotrexateloaded lipid-core nanocapsules (MTX-LNC) prepared in a liquid-dose form reduce proinflammatory and T-cell-derived cytokines on activated mononuclear cells derived from RA patients, even in functional MTX-resistant conditions, and whether the MTX-LNC are able to reduce inflammation at lower doses than an MTX solution in an experimental model of inflammatory arthritis.

\section{Materials and methods Materials}

PCL (molecular weight $[\mathrm{MW}]=65,000 \mathrm{~g} \cdot \mathrm{mol}^{-1}$ ) was supplied by Sigma-Aldrich Co (St Louis, MO, USA). Caprylic/ capric triglyceride was obtained from Delaware (Brazil) and polysorbate 80 was obtained from Brasquim (Porto Alegre, Brazil). Span ${ }^{\circledR} 60$ (sorbitan monostearate) was obtained from Sigma-Aldrich Co. MTX was supplied by Pharma Nostra (Anápolis, Brazil). All other chemicals and solvents used were of analytical or pharmaceutical grade. All reagents were used as received.

\section{Methods}

\section{Preparation of the LNC dispersed in water}

The LNC formulations were prepared using a self-assembling method as previously described. ${ }^{26}$ An acetone solution $(27 \mathrm{~mL})$, at $40^{\circ} \mathrm{C}$, that contained PCL $(0.100 \mathrm{~g})$, sorbitan monostearate $(0.038 \mathrm{~g})$, caprylic/capric triglyceride (0.160 g), and MTX (0.0025 g) was injected into an aqueous solution $(53 \mathrm{~mL})$, which contained polysorbate 80 $(0.077 \mathrm{~g})$ at $40^{\circ} \mathrm{C}$. A turbid solution was instantaneously obtained, which was maintained under magnetic stirring for 10 minutes. Acetone was then eliminated, and the suspension was concentrated under reduced pressure at $40^{\circ} \mathrm{C}$ 
to approximately $9 \mathrm{~mL}$. The final volume was adjusted to $10 \mathrm{~mL}$ in a volumetric flask. The two LNC formulations were named (1) MTX-LNC, containing $0.250 \mathrm{mg} \cdot \mathrm{mL}^{-1}$ of MTX, and (2) LNC, without MTX.

\section{Physicochemical characterization of the formulations Particle sizing}

The formulations were analyzed by laser diffraction (Mastersizer $^{\circledR}$ 2000, Malvern Instruments, Malvern, UK) to determine the particle-size distribution profiles in the range of $40 \mathrm{~nm}$ to $2 \mathrm{~mm}$, the volume-weighted mean diameters $(\mathrm{D}[4,3])$, and the polydispersity of the particle sizes was expressed as span, which is calculated using the diameters at $10 \%, 50 \%$, and $90 \%$ of the cumulative size distribution. The MTX-LNC and LNC were analyzed by adding the formulations directly to the wet unit that contained distilled water at room temperature. No treatment or purification was conducted prior to analysis. The measurements were performed 24 hours after preparation in triplicate batches.

To determine the particle-size distributions with more precision, the formulations were analyzed by photon correlation spectroscopy in the range from 1 to $5 \mathrm{~mm}$. Diluted samples were analyzed with a Zetasizer Nano ZS instrument (Malvern Instruments Ltd). For the photon correlation spectroscopy analysis, the hydrodynamic diameter $(\mathrm{D} h)$ was calculated using the method of cumulants, and the polydispersity index (PDI) was calculated using the relative variance in the particle-size distribution. The measurements were performed at $25^{\circ} \mathrm{C}$ after diluting the samples $(500 \times$, without previous treatment) with ultrapure water.

Nanoparticle tracking analysis (NTA) was performed using a NanoSight LM10 instrument (Malvern Instruments Ltd) to better characterize the polydispersity of the formulations. The median diameter (D50), diameter at the 90th percentile (D90) under the cumulative size distribution, and the particle number density were analyzed using Brownian motion in real-time via a CCD camera. Each video clip was captured over 60 seconds at $25^{\circ} \mathrm{C} \pm 4^{\circ} \mathrm{C}$ and $0.90 \pm 0.09 \mathrm{cP}$ after the formulations were diluted $(5,000 \times)$ in pre-filtered water $\left(\right.$ Milli- $\left.Q^{\circledR}\right)$.

\section{$\mathrm{pH}$ measurements}

The $\mathrm{pH}$ values of the formulations were measured without previous dilution using a calibrated B474 potentiometer (Micronal, SA, São Paulo, Brazil) at $25^{\circ} \mathrm{C}$.

\section{Electrophoretic mobility and zeta potential}

The zeta potential values were calculated by determining the electrophoretic mobility after dispersing the sample in
$10 \mathrm{mM} \mathrm{NaCl}$ aqueous solution. Measurements were performed using the aforementioned Zetasizer Nano ZS.

\section{Quantification of MTX in the MTX-LNC, drug content, and encapsulation efficiency}

To quantify the drug content in the formulation, the MTXLNC were dissolved in acetonitrile-tetrahydrofuran $(4: 6, \mathrm{v} / \mathrm{v})$. The final solution was filtered $\left(0.45 \mu \mathrm{m}\right.$, Millipore $\left.{ }^{\circledR}\right)$, injected $(20 \mu \mathrm{L})$, and quantified ( $\lambda=303 \mathrm{~nm}$ ) using high-performance liquid chromatography on a PerkinElmer S-200 with an S-200 injector, a UV-visible light detector, a guard column (PerkinElmer Inc, Waltham, MA, USA), and a Spherisorb ${ }^{\circledR}$ ODS2 column $(150 \times 4 \mathrm{~mm}, 4 \mu \mathrm{m}$; Waters Corporation, Milford, MA USA). The mobile phase $\left(0.8 \mathrm{~mL} \cdot \mathrm{min}^{-1}\right)$ was adapted from a previously reported method, ${ }^{27}$ which consisted of water-methanol-tetrahydrofuran (70:20:10, v/v/v) adjusted to an apparent $\mathrm{pH}$ of $6.0 \pm 0.5$ with $10 \%(\mathrm{v} / \mathrm{v})$ acetic acid. The method was validated by demonstrating the linear analytical curves in the range of $2.00-50.00 \mu \mathrm{g} \cdot \mathrm{mL}^{-1}$ with correlation coefficients ( $r$ ) higher than 0.99 , an accuracy of $99 \%$, and coefficients of variation for precision and reproducibility lower than $4 \%$. The limit of quantification was $2 \mu \mathrm{g} \cdot \mathrm{mL}^{-1}$.

Additionally, the encapsulation efficiency was calculated from the difference between the total drug content (total concentration of the drug in the formulation) and the concentration of the drug dissolved in the continuous phase divided by the drug content and multiplied by 100 . The drug concentration in the continuous phase was determined by ultrafiltration centrifugation without previous treatment of the MTX-LNC. The ultrafiltrate was directly analyzed using high-performance liquid chromatography after the separation of MTX dissolved in the continuous phase of the formulation at $1,844 \times g(\mathrm{RCF})$ for 5 minutes using a Microcon ${ }^{\circledR}$ Centrifugal Filter device (10,000 Da; EMD Millipore, Billerica, MA, USA) in a centrifuge (Sigma ${ }^{\circledR}$ 1-14 Microfuge; Sigma Laborzentrifugen GmbH, Osterode am Harz, Germany).

\section{Animals}

Twenty-four 8-week-old Lewis rats that weighed between 250 and $350 \mathrm{~g}$ were maintained in the biotherium at the Federal University of Amazonas (UFAM) and used in the experiment. The animals had ad libitum access to water and food and were maintained in a light-controlled (12-hour light-dark cycle) and temperature-controlled $\left(22^{\circ} \mathrm{C}\right)$ environment. Sixteen animals were randomized into four groups, and two animals were maintained in each cage. All experiments were performed with the approval of the Institutional 
Committee for Ethics in Animal Experiments under reference number 010/2010 (CEEA) UFAM.

\section{Arthritis induced by Freund's Complete Adjuvant}

Arthritis was induced in animals on the first day of the experiment via the intradermic injection of $0.1 \mathrm{~mL}$ of Freund's complete adjuvant (Difco $\left.{ }^{\circledR}\right)$ at the base of the tail ${ }^{28}$ after brief inhalation anesthesia with isoflurane. When the signs of arthritis were evident, the animals were divided into four groups by raffling the animals into one of the following groups: Group 1 - control (arthritis without treatment); Group 2 - arthritis with LNC; Group 3 - MTX; and Group 4 MTX-LNC. From the 14th day of the experiment, when the signs of arthritis were evident, LNC, MTX, or MTX-LNC were initiated by intraperitoneal injection. The MTX was diluted in saline solution under sterile conditions to give a final concentration of $1 \mathrm{mg} / \mathrm{mL}$, and the final volume injection was the same for both MTX and MTX-LNC formulations. The MTX dose was $1.5 \mathrm{mg} \cdot \mathrm{kg}^{-1}$.week, and the MTX-LNC dose was $0.375 \mathrm{mg} \cdot \mathrm{kg}^{-1} \cdot$ week. On the 28th day of the experiment, the animals were killed by profound inhalation of isoflurane, and blood samples were collected by heart puncture.

\section{Assessment of edema in the rat paw and arthritis score}

Paw swelling was assessed by a trained observer who had not been involved in the planning of the experiment (blind assessment). Paw volumes were measured on days $0,7,14$, 21 , and 28 of the experiment with a digital plethysmometer (Insight $^{\circledR}$, Brazil). Arthritis was also evaluated by physical examination of the paws on the 28th day of the experiment using an arthritis score as described here: briefly, the intensity of arthritis was scored by grading each paw using the clinical signs of arthritis (erythema, swelling, and deformity) as follows: 0 - no erythema or swelling; 1 - slight erythema or swelling of one toe or finger; 2 - erythema and swelling of more than one toe or finger; 3 - erythema and swelling of the ankle or wrist; and 4 - complete erythema and swelling of the toes or fingers and the ankle or wrist and an inability to bend the ankle or wrist. All four paws were scored; thus, the highest possible arthritic index score was 16 .

\section{Quantification of the cytokines tumor necrosis factor- $\alpha$ (TNF- $\alpha$ ), interleukin (IL)- I $\alpha$, and C-reactive protein (CRP)}

Serum concentrations of the cytokines TNF- $\alpha$ and IL- $1 \alpha$ were measured using a cytometric bead array (CBA) with
CBA Flex Sets ${ }^{\circledR}$ for TNF- $\alpha$ and IL-1 $\alpha$ (BD Biosciences, San Jose, CA, USA) in accordance with the manufacturer's instructions. A FACSCalibur ${ }^{\mathrm{TM}}$ flow cytometer (BD Biosciences) was used to read the samples. The concentrations $(\mathrm{pg} / \mathrm{mL})$ and mean fluorescence intensities of each cytokine were calculated using BD FCAP Array ${ }^{\mathrm{TM}}$ Software (v 1.0.1; BD Biosciences). CRP was measured in the serum samples using a Roche Hitachi Chemistry Analyzer and immunoturbidimetric assay (catalogue number: 4956842190) following the manufacturer's instructions. The CRP final concentrations are expressed as $\mathrm{mg} / \mathrm{dL}$.

\section{Effects of MTX-LNC on human peripheral blood and synovial fluid mononuclear cells}

All procedures that involved humans, directly or indirectly, were approved by the Committee for Ethics in Research with Humans, Hospital Geral Adriano Jorge, Manaus, Brazil (reference number CAAE - 0016.0.0193.000-11), in accordance with Brazilian law, which complies with the Declaration of Helsinki. All subjects were individually informed about the proposed study and agreed to participate by signing a written informed consent form. During corticoid joint injection procedures at the Rheumatoid Arthritis Clinic, Adriano Jorge Hospital, $40 \mathrm{~mL}$ of synovial fluid from RA patients was collected in sterile conditions and stored in polypropylene tubes. The human mononucleated cells were separated and harvested from synovial fluid immediately, using a FicollHypaque $^{\circledR}$ (GE Healthcare Bio-Sciences AB, Uppsala, Sweden) gradient. The harvested mononuclear synovial cells were cultured using fully Roswell Park Memorial Institute medium 1640 (Sigma-Aldrich Co), supplemented with $20 \%$ fetal bovine serum $\left(\right.$ Gibco $^{\circledR}$, Thermo Fisher Scientific, Waltham, MA, USA) and 5\% streptomycin. The cells were subsequently incubated at $37^{\circ} \mathrm{C}$ in an atmosphere of $95 \%$ humidified air and $5 \% \mathrm{CO}_{2}$ for 4 hours, with different doses of conventional MTX, MTX-LNC, and LNC. Peripheral blood mononuclear cells (PBMCs) from $20 \mathrm{~mL}$ of peripheral blood obtained from healthy individuals were separated and cultured with the same technique. However, prior to incubation with MTX formulations, these cells were activated using 4 $\beta$-phorbol-12-myristate 13-acetate (PMA) (5 nM). After activation, the cells were also incubated at $37^{\circ} \mathrm{C}$ in an atmosphere of $95 \%$ humidified air and $5 \% \mathrm{CO}_{2}$ for 4 hours with different doses of conventional MTX, MTX-LNC, and LNC. After 4 hours, the culture supernatants were collected, and Th1, Th2, and Th17 cytokines were quantified using a CBA with a Human CBA Th1/Th2/T17 Kit (BD Biosciences; 
catalogue number: 560484) as previously described for the other cytokines.

\section{Statistical analysis}

The results are expressed as the means and standard deviations, and a 95\% confidence interval was used. One-way or two-way analyses of variance (ANOVAs) were used to compare the means, and a Tukey's test or linear test for trend was used for post-hoc analysis. The Mann-Whitney test was used when normality was not observed. Linear regression and curve fitting with nonlinear polynomial regression were applied to study the effects of the different MTX preparations on the cytokine levels in the blood and synovial culture cells. A significance level of $\alpha=0.05$ was adopted, and all $P$-values were two tailed.

\section{Results}

\section{Preparation of MTX-LNC dispersed in water}

The LNC formulation macroscopically exhibited a homogeneous, milky appearance, and the MTX-LNC formulation macroscopically appeared as an opaque yellow liquid. The total drug content in the MTX-LNC liquid formulation was $0.251 \pm 0.010 \mathrm{mg} \cdot \mathrm{mL}^{-1}$, and the encapsulation efficiency was $20.0 \% \pm 3.0 \%$. The $\mathrm{pH}$ values of the formulations were 4.8 and 5.8, respectively (Table 1). The volume-weighted average diameter, D[4.3], was $172 \pm 21 \mathrm{~nm}(\mathrm{LNC})$ and $175 \pm 17 \mathrm{~nm}$

Table I Characterization of the formulations by potentiometry, laser diffraction, photon correlation spectroscopy, and nanoparticle tracking analysis

\begin{tabular}{|c|c|c|}
\hline & LNC & MTX-LNC \\
\hline \multicolumn{3}{|l|}{ Potentiometry } \\
\hline $\mathrm{pH}$ & $5.8 \pm 0.2$ & $4.8 \pm 0.5$ \\
\hline \multicolumn{3}{|l|}{ Laser diffraction } \\
\hline $\mathrm{D}[4.3](\mathrm{nm})$ & $|72 \pm 2|$ & $175 \pm 17$ \\
\hline Span & $1.5 \pm 0.2$ & $1.6 \pm 0.2$ \\
\hline \multicolumn{3}{|l|}{ Photon correlation spectroscopy } \\
\hline $\mathrm{Dh}(\mathrm{nm})$ & $188 \pm 14$ & $194 \pm 6$ \\
\hline PDI & $0.07 \pm 0.03$ & $0.1 \mathrm{I} \pm 0.0 \mathrm{I}$ \\
\hline \multicolumn{3}{|l|}{ Electrophoretic mobility } \\
\hline Zeta potential (mV) & $-13 \pm 1$ & $-8 \pm 1$ \\
\hline \multicolumn{3}{|l|}{ Nanoparticle tracking analysis } \\
\hline Mean diameter $(\mathrm{nm})$ & $191 \pm 2$ & $215 \pm 9$ \\
\hline $\mathrm{D} 50(\mathrm{~nm})$ & $18 \mid \pm 4$ & $203 \pm I I$ \\
\hline $\mathrm{D} 90(\mathrm{~nm})$ & $27 I \pm I I$ & $309 \pm 10$ \\
\hline PND $\left(\times 10^{12}\right.$ particles $\left.\mathrm{mL}^{-1}\right)$ & $4.55 \pm 0.80$ & $4.64 \pm 0.40$ \\
\hline
\end{tabular}

Note: Data presented as mean \pm standard deviation.

Abbreviations: D[4.3], volume-weighted average diameter; D50, median diameter; $\mathrm{D} 90$, the diameter at the 90th percentile; Dh, hydrodynamic diameter; LNC, blank lipid-core nanocapsules; MTX-LNC, methotrexate-loaded lipid-core nanocapsules; PDI, polydispersity index; PND, particle number density.
(MTX-LNC), and the span values were smaller than 1.6 \pm 0.2 for both formulations. The $\mathrm{D} h$ was approximately $190 \mathrm{~nm}$ with a PDI lower than 0.11 (Figure 1). Regarding the NTA, the mean size, D50 and D90, were $191 \pm 2,181 \pm 4$, and $271 \pm 11$, respectively, for $\mathrm{LNC}$, and $215 \pm 9,203 \pm 11$, and $309 \pm 10$, respectively, for MTX-LNC. The particle number densities for the formulations were $4.55 \times 10^{12}$ and $4.64 \times 10^{12}$ particles $\mathrm{mL}^{-1}$, respectively. The results are summarized in Table 1 .

\section{Lower doses of MTX-LNC achieve the same effect as higher doses of MTX}

Figure $2 \mathrm{~A}$ and $\mathrm{B}$ shows the arthritis kinetics of rat paws for 28 days in the different groups. On the 28th day of the experiment, the hind paw volume was similar for both MTX and MTX-LNC (1.275 and $1.225 \mathrm{~mL}$, respectively; $P=0.951)$. However, it should be stressed that the dose of MTX in the MTX-LNC used was actually $75 \%$ lower than that of the MTX in the MTX group. These results strongly suggest MTX-LNC are highly effective, even at a lower dose regime than MTX.

\section{MTX-LNC have early effects compared with MTX in the reduction of arthritis}

Figure 2A clearly demonstrates the strong arthritis-reducing effect of MTX-LNC was present on the 21st day of the experiment compared with the control group $(P<0.0001)$ and MTX group ( $P=0.0018)$. This effect was significantly sustained on the 24th and 26th days of the experiment $(P=0.0027$ and $P=0.049$, respectively) compared with the MTX group. These data indicate a low dose of MTX-LNC had an early effect compared with MTX alone in the reduction of adjuvant arthritis in rats.

\section{MTX-LNC reduce the serum levels of proinflammatory cytokines and CRP}

The serum levels of TNF- $\alpha$ were significantly lower in the MTX-LNC group than in the MTX group using Tukey's test $(P=0.0114$, Figure $3 \mathrm{~A})$. The serum IL- $1 \alpha$ levels were similar for both groups when the comparison was performed using Tukey's test $(P=0.778)$; however, the linear test for trend indicated a significant trend $(P=0.0001)$. The CRP levels were also lower for the MTX-LNC group than the MTX group (Tukey's test, $P=0.011$, Figure 3B).

\section{MTX-LNC reduce the production of proinflammatory and T-cell-derived} cytokines in a dose-dependent manner When the MTX and MTX-LNC were incubated with synovial mononuclear cells (Figure 4), the MTX-LNC substantially 
A
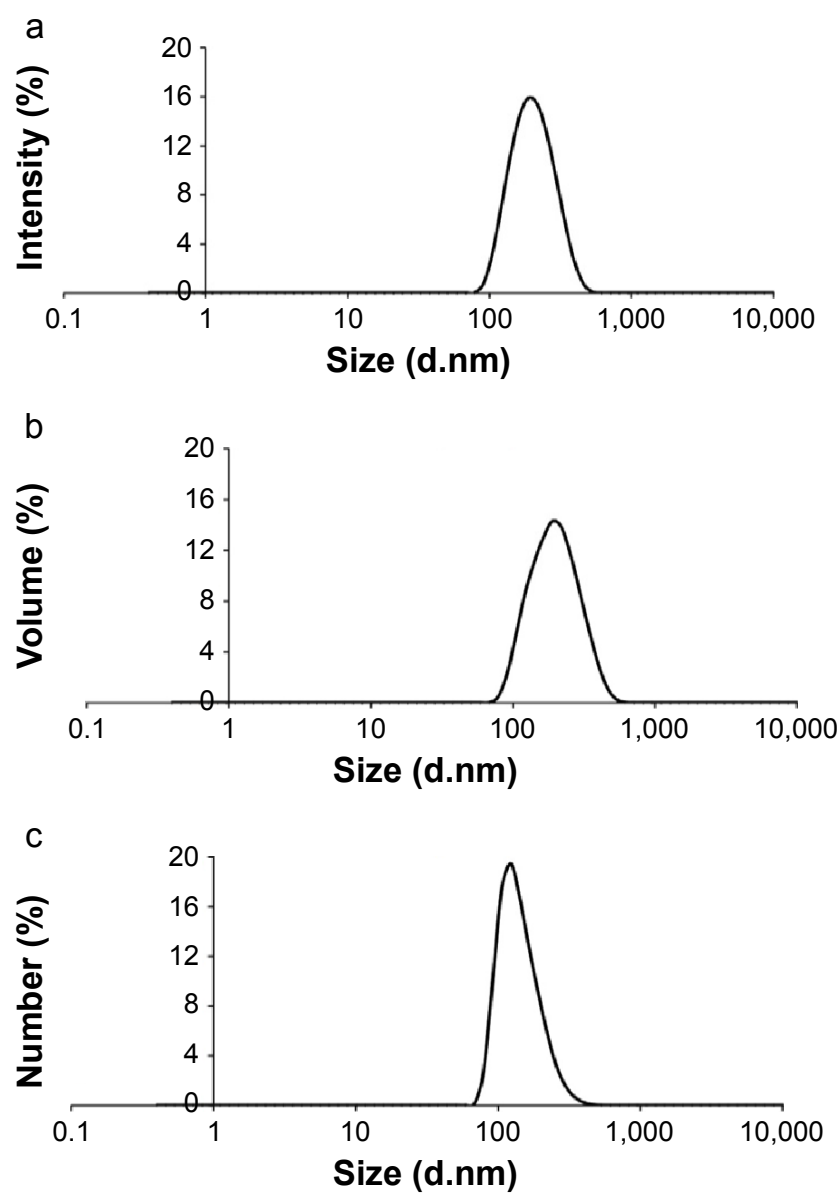

B
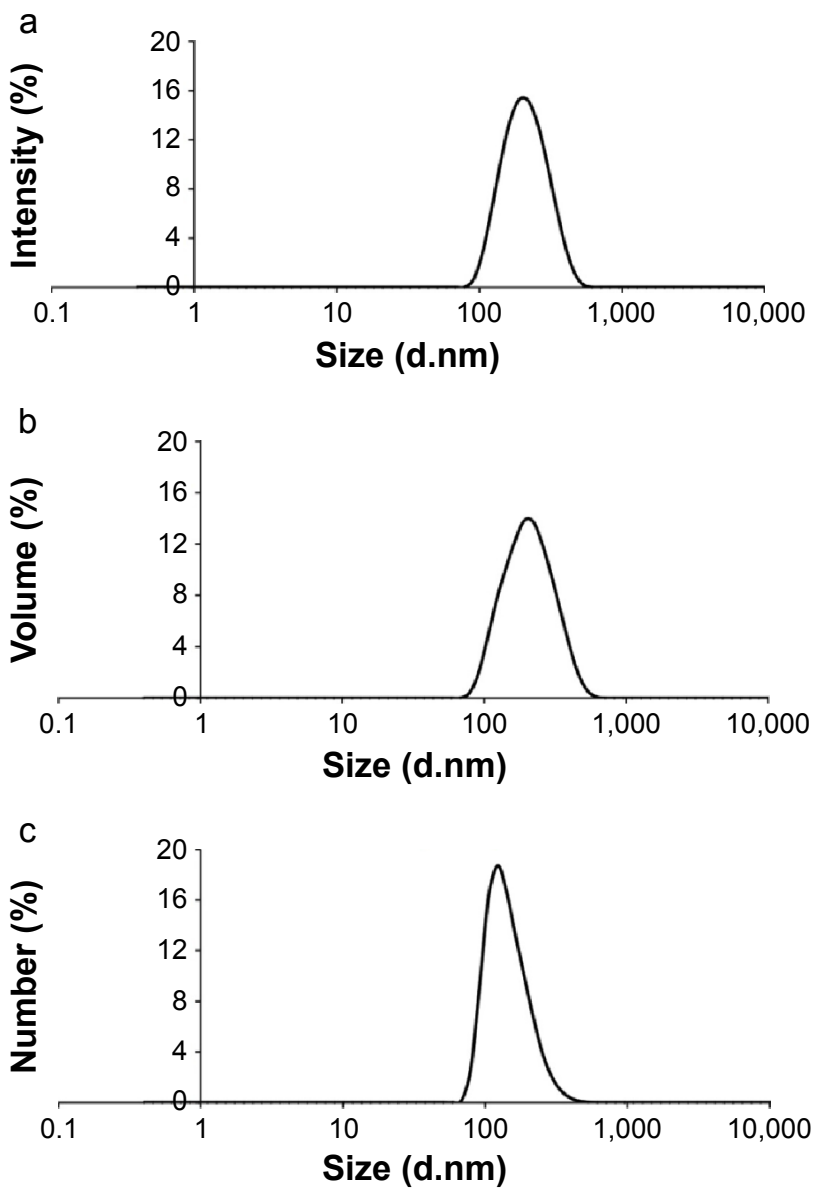

Figure I Particle-size analysis by photon correlation spectroscopy.

Notes: (A) LNC: (a) intensity, (b) volume, (c) number; (B) MTX-LNC: (a) intensity, (b) volume, (c) number.

Abbreviations: LNC, blank lipid-core nanocapsules; MTX, methotrexate; MTX-LNC, MTX-loaded lipid-core nanocapsules.
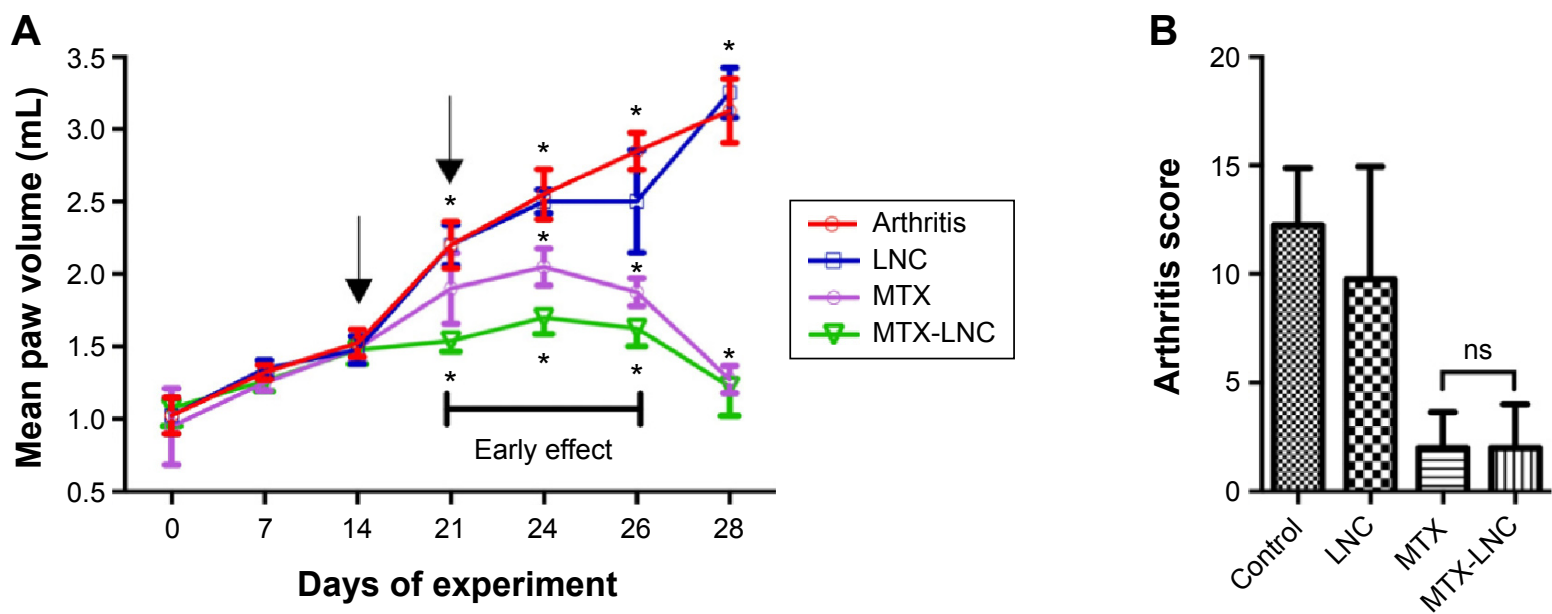

Figure 2 Arthritis kinetics and scores for 28 days.

Notes: (A) Arthritis kinetics. The mean volume of the hind paws was similar for MTX and MTX-LNC on the last day of experiments $(P=0.95 \mathrm{I})$. (B) Arthritis scores on the 28th day of the experiment. Arthritis scores were similar for MTX and MTX-LNC ( $P=0.999)$. The scores for MTX and MTX-LNC were significantly different from that for the control group $(P=0.004$ and $P=0,008$, respectively). $M T X$ and MTX-LNC were also different from the $L N C$ group $(P=0.028$ and $P=0.042$, respectively). All data were analyzed using one-way analysis of variance and Tukey's test. (A) The black arrows indicate the days when medications were administered. $* P<0.05$.

Abbreviations: LNC, blank lipid-core nanocapsules; MTX, methotrexate; MTX-LNC, MTX-loaded lipid-core nanocapsules; ns, nonsignificant. 

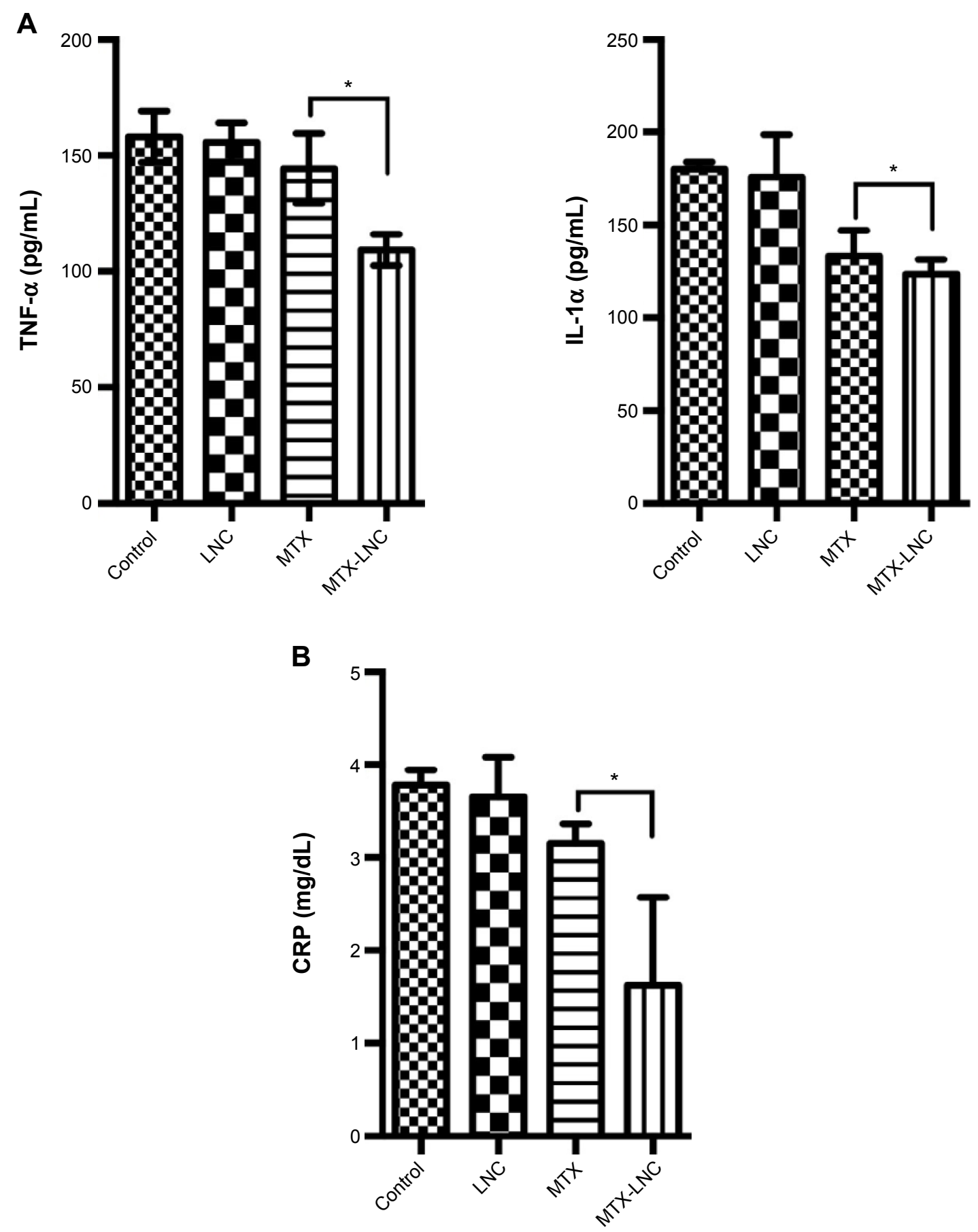

Figure 3 Serum inflammatory markers on day 28 of the experiment.

Notes: (A) Quantification of the proinflammatory cytokines TNF- $\alpha$ and IL-I $\alpha$. There was a significant difference between TNF- $\alpha$ levels for MTX and MTX-LNC (144.5 \pm 15.06 and 109.3 \pm 6.75 , respectively, $P=0.0114$ [Tukey's test]). IL-I $\alpha$ serum levels showed a linear decreasing trend, with lower levels for MTX-LNC (post-test for linear trend, $P=0.000 \mathrm{I})$. (B) Serum levels of CRP for the MTX and MTX-LNC groups. The mean serum CRP level was different for MTX and MTX-LNC (3.16 \pm 0.20 and I.62 \pm 0.94 , respectively, $P=0.01$ I [Tukey's test]); those for LNC $(3.65 \pm 0.43)$ and MTX $(3.16 \pm 0.20)$ were not different from that of the control group $(3.78 \pm 0.16)(P=0.989$ and $P=0.484$, respectively [Tukey's test]). $* P<0.05$.

Abbreviations: CRP, C-reactive protein; IL-I $\alpha$, interleukin-I alpha; LNC, blank lipid-core nanocapsules; MTX, methotrexate; MTX-LNC, MTX-loaded lipid-core nanocapsules; TNF- $\alpha$, tumor necrosis factor-alpha.

reduced both the proinflammatory cytokines, including TNF- $\alpha$ and IL-6 ( $P=0.046$ and $P=0.033$, respectively), and T-cell-derived cytokines, including interferon-gamma (INF- $\gamma$ ) and IL-17A ( $P=0.046$ and $P=0.006$, respectively) compared with MTX. More importantly, the polynomial trend lines indicated a dose-dependent effect of MTX-LNC on the reduction of cytokines: TNF- $\alpha\left(r^{2}=0.89, P=0.001\right)$, IL-6 $\left(r^{2}=0.68, P=0.0061\right)$, IL-17A $\left(r^{2}=0.84, P=0.001\right)$, and INF- $\gamma\left(r^{2}=0.94, P=0.001\right)$. Of note, when PBMCs from the healthy controls were previously treated with PMA 

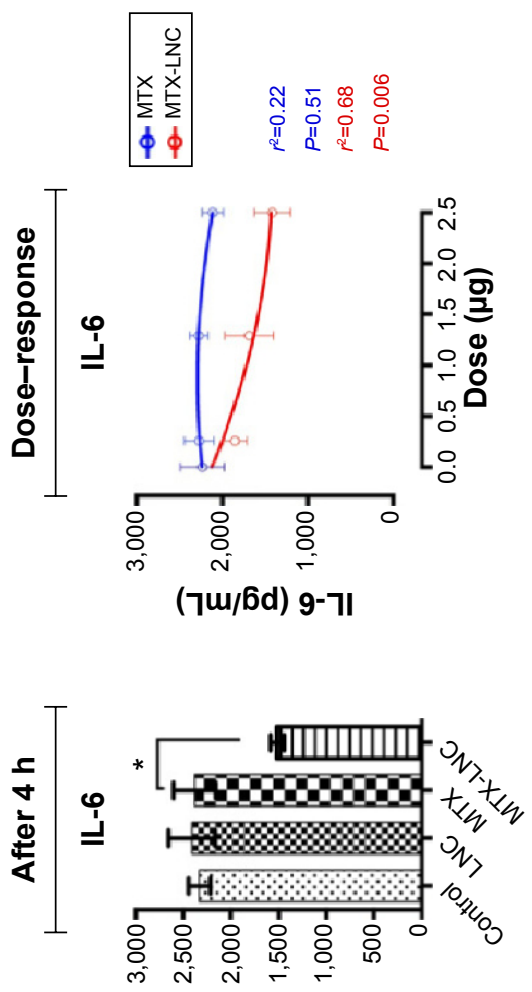

( )
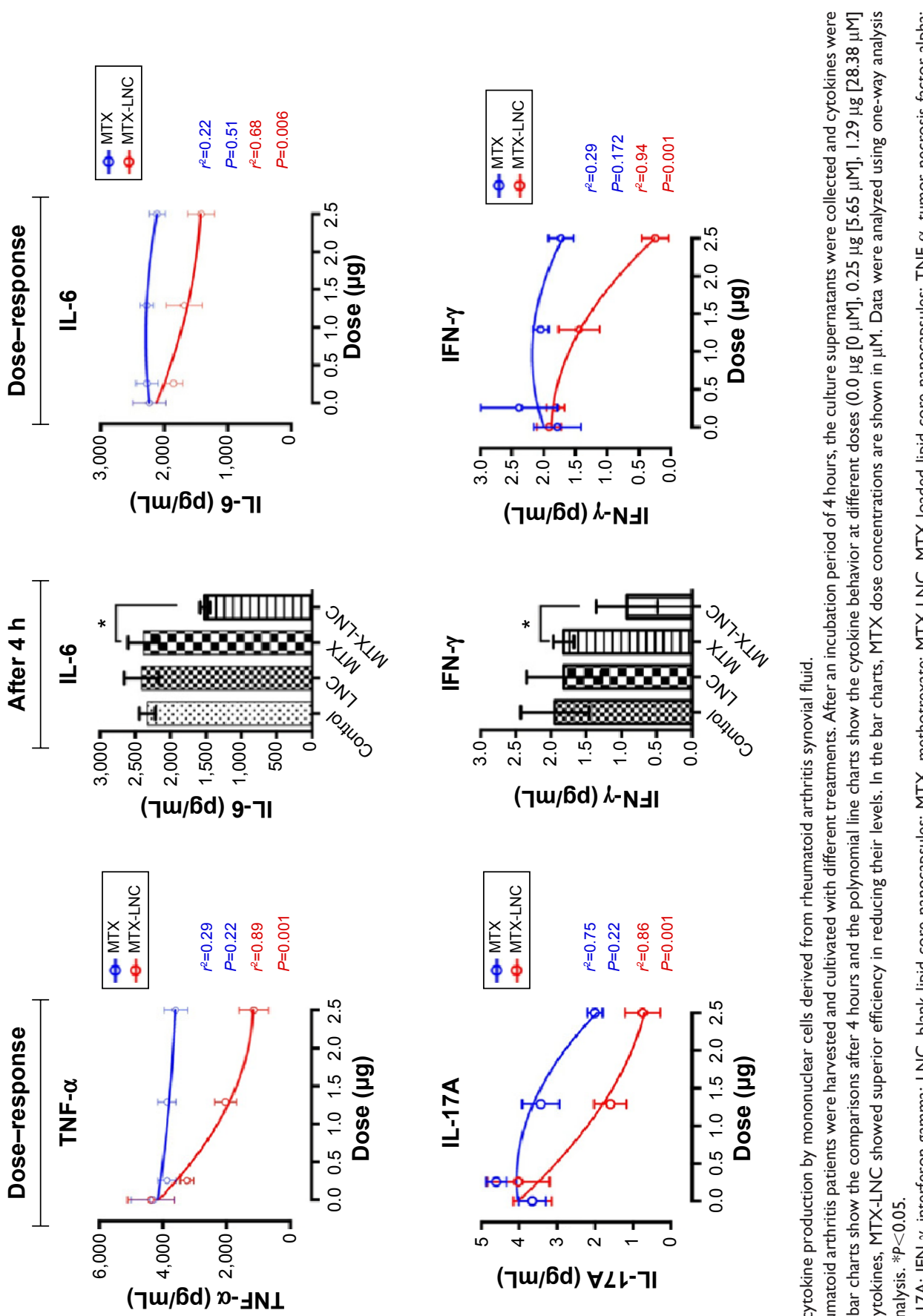

$(7 \mathrm{~m} / 6 \mathrm{~d}) \boldsymbol{l}$-N I

(ךu/6d) $\forall L$ -
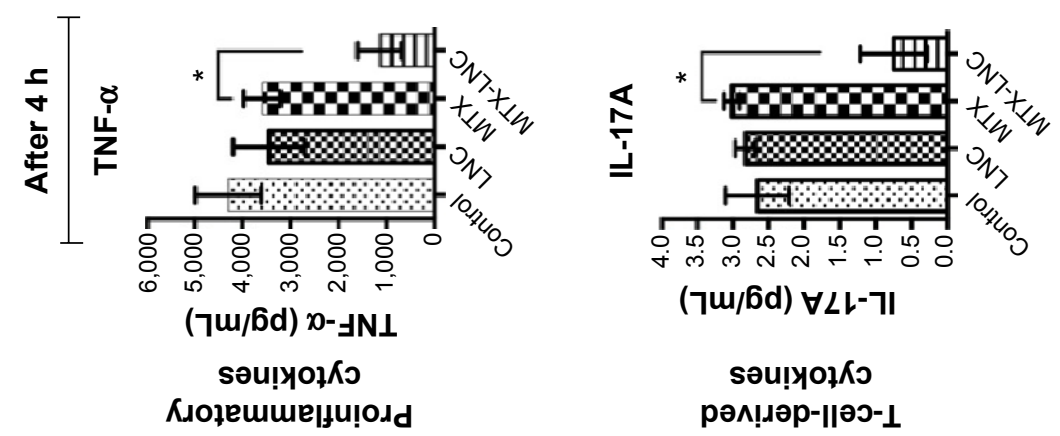

sәu!yolरo

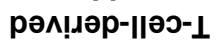

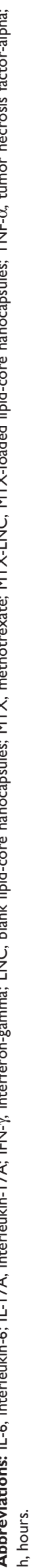



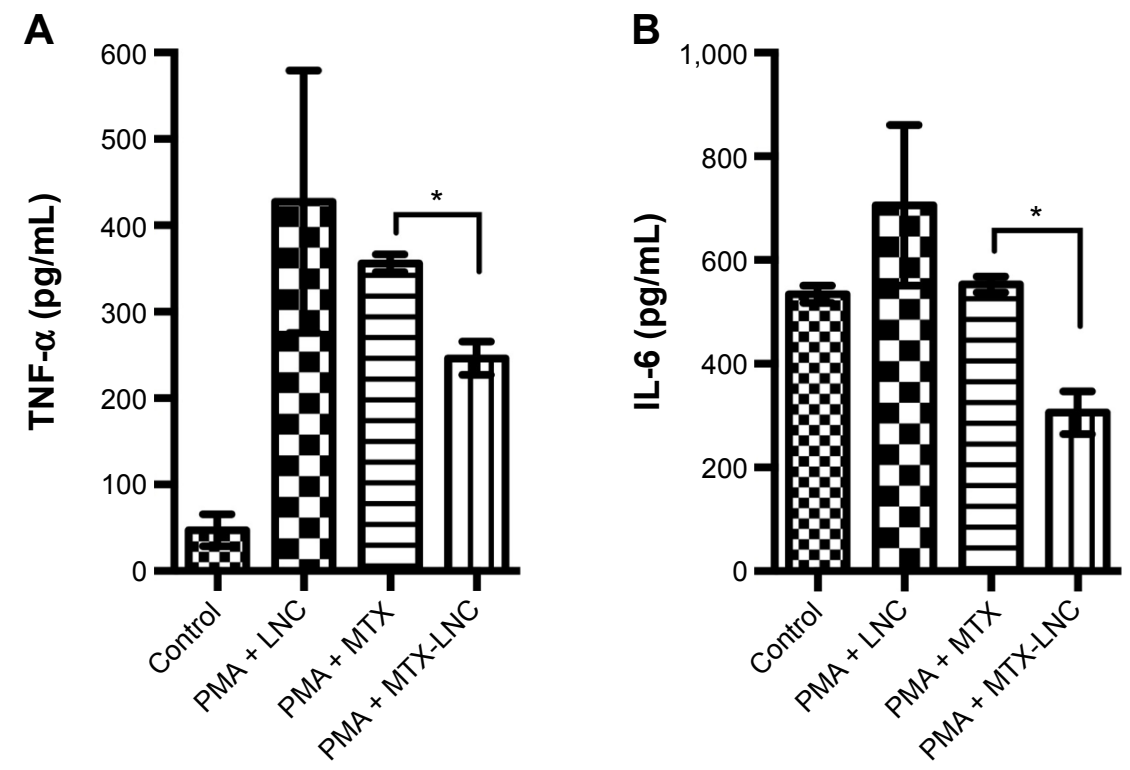

Figure 5 The effects of the MTX-LNC formulation on (A) TNF- $\alpha$ and (B) IL-6 production in PBMCs stimulated with PMA.

Notes: The cultures of stimulated PBMCs from healthy individuals showed reduction in TNF- $\alpha$ and IL- 6 production by MTX-LNC. The TNF- $\alpha$ and IL-6 levels were lower in the MTX-LNC group and statistically different from those in the PMA-LNC $(P=0.016$ and $P=0.018$, respectively) and $P M A-M T X$ groups $(P=0.034$ and $P=0.045$, respectively). For the analysis-of-variance multiple comparisons, Tukey's test was applied. $* P<0.05$.

Abbreviations: IL-6, interleukin-6; LNC, blank lipid-core nanocapsules; MTX, methotrexate; MTX-LNC, MTX-loaded lipid-core nanocapsules; PBMCs, peripheral blood

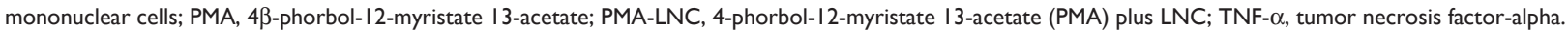

(Figure 5) in the MTX resistance model in vitro, as expected, we identified a loss of MTX effects on the reduction of the cytokines TNF- $\alpha$ and IL- 6 compared with the PMA-LNC group (one-way ANOVA, $P=0.578$ and $P=0.411$, respectively). However, the MTX-LNC still reduced both TNF- $\alpha$ and IL-6 compared with MTX (one-way ANOVA, $P=0.034$ and $P=0.045$, respectively). In addition, the TNF- $\alpha$ and IL-6 levels for MTX-LNC were different from those for PMA-LNC ( $P=0.016$ and $P=0.018$, respectively), which indicates a consistent effect against MTX under cellular resistance conditions.

\section{Discussion}

The encapsulation of drugs in LNC has benefits, such as improved drug efficacy and decreased side effects, in the treatment of several diseases. ${ }^{25,29-31}$ The formulations used in this study, MTX-LNC and LNC, exhibited unimodal particle-size distribution profiles by laser diffraction with nanoscopic z-average diameter and PDIs $<0.2$, which demonstrate narrow nanoscopic particle-size distributions and a D90 < 309 \pm 10 (NTA). The physicochemical parameters indicate that the formulation is adequate for intravenous administration. This route of administration has an advantage over other routes because high serum levels of the drug are promptly achieved, which provides wide access to the inflammatory sites because only one application is needed compared with other routes, such as intra-articular; thus, this is useful in reducing the number of patients who might discontinue the therapy. Moreover, it is well demonstrated that the LNC formulation has no potential for either acute or sub-chronic toxicity in vivo. ${ }^{32,33}$ The loading of MTX on LNC provides a stable pharmaceutical formulation with a high concentration in inflammatory sites.

MTX is widely used in the treatment of rheumatic and non-rheumatic conditions. Therapies approved for RA treatment have commonly been tested using adjuvant-induced arthritis. ${ }^{34}$ Thus, previous studies demonstrated that the intraarticular administration of both MTX lipid nanoemulsion and liposomally conjugated MTX is able to reduce leukocytes in the synovial fluid and membrane, as well as those retained in rat arthritic joints. ${ }^{35,36}$ It has also been demonstrated that PEGylated MTX liposomes and chitosan-coated formulations selectively reach the target site with reduced toxicity to other organs. ${ }^{37}$ However, these studies could not fully evaluate the role of nano-encapsulated MTX on cytokine levels. In the study reported here, we demonstrated that MTX-LNC not only reduce adjuvant arthritis but also could achieve arthritis control at lower doses than a conventional MTX formulation. Moreover, we also identified an early effect on the reduction of arthritis after the first MTX-LNC administration. These findings may be important for current RA treatment protocols, in which high standards of disease activity control are 
recommended at 6 to 12 months as an approach to improve disease outcome and prognosis. ${ }^{38,39}$

TNF- $\alpha$, IL- $1 \alpha$, and IL- 6 are proinflammatory cytokines produced by a range of different cell types, but mainly by macrophages and antigen-presenting cells, including activated synovial macrophages and fibroblasts. ${ }^{40,41}$ These cytokines are strictly related to systemic and synovial membrane inflammations in RA patients. ${ }^{5}$ Several biologic therapies that target these cytokines are currently in use as a mechanism to improve efficient clinical disease control. ${ }^{39}$ We demonstrated here that at lower doses, MTX-LNC were more effective in the reduction of TNF- $\alpha$ and IL- $1 \alpha$ in adjuvant-induced arthritis than conventional MTX. The lower CRP serum levels in the MTX-LNC-treated animals may reflect the reduction of IL- 6 that induces CRP production in the liver. Moreover, the MTX-LNC reduced the proinflammatory, INF- $\gamma$, and IL-17A cytokine production on mononuclear cells derived from the synovial fluid of RA patients, which indicates the potential to reduce the Th1 and Th17 responses in vivo that represent the major $\mathrm{T}$-cell responses implicated in the immunopathogenesis of RA. ${ }^{5}$

MTX reduces the blood levels of cytokines, as well as cytokine tissue production and inflammation; it is related to the intracellular concentrations of MTX polyglutamates that inhibit the phosphoribosylaminoimidazolecarboxamide formyltransferase (AICAR) transformylase enzyme, which leads to the accumulation of adenosine in the extracellular fluid. ${ }^{11}$ Optimal concentrations of MTX at the inflammatory site, as well as at the intracellular compartment, are essential steps to suppress inflammation at the synovial membrane. Thus, the superior effect of MTX-LNC at reducing inflammation is most likely a result of the ability of LNC to improve the intracellular concentrations of MTX. Remarkably, the ability of the MTX-LNC formulation to reduce cytokine production of mononuclear synovial cells was enhanced in a dose-dependent manner, which reflects cellular uptake and demonstrates that the intracellular concentrations of MTXLNC could be improved by increasing the MTX-LNC dose regimes. To understand these effects, we should highlight that LNC are able to concentrate at macrophage endocytic intracellular vesicles, which serve as a drug transmembrane delivery system. ${ }^{22}$ It is also interesting to note that this transmembrane transport ability enables the drug's actions on cellular sign pathways. ${ }^{42}$ Moreover, we have previously demonstrated that LNC that contain an MTX derivative are more efficient in the induction of apoptosis than the drug in solution, ${ }^{25}$ and this effect may also have been implicated in the reduction of inflammation at the synovial membrane, perhaps via the induction of synovial macrophage apoptosis. The capacity of the LNC to increase the drug's action on the reduction of proinflammatory cytokines has also been demonstrated in a rat arthritis model, in which LNC that contained indomethacin (IndOH-LNC) reduced cytokines; however, there was no significant effect for the drug in solution. $^{43}$

Finally, resistance to MTX is another current issue in the treatment of RA because it compromises clinical responsiveness to the drug. Resistance to MTX occurs because of a wide range of mechanisms, including MTX uptake by a reduced folate carrier, an increase of MTX efflux, a decrease of MTX polyglutamation, and an overexpression of dihydrofolate reductase. ${ }^{44,45}$ In this work, we examined whether MTX-LNC's cytokine level-reducing effects were sustained under cellular resistance to MTX. For this purpose, we treated human PBMCs with PMA. PMA is a potent activator of protein kinase $\theta$, which induces the expression of TNF- $\alpha$ and IL-6 as a result of the overexpression of nuclear factor kappa-B; most important here, PMA induces the intracellular expression of the transcription factors Sp1 and dihydrofolate reductase. ${ }^{46}$ The MTX-LNC were more effective than MTX even in these conditions, which is in accordance with our previous results for neoplastic cells. ${ }^{25}$ Again, the ability of LNC that carry MTX to concentrate the drug inside the cells plays a central role in these actions. ${ }^{22}$ This feature should be important with current RA treatments for MTX unresponsive patients who commonly set up treatment until biologics is introduced to RA treatment, raising the costs associated with the disease.

\section{Conclusion}

For the first time, as far as we are aware, this work has demonstrated the anti-inflammatory properties of MTX-LNC on autoimmunity using a range of both in vivo and in vitro biological assays. The MTX-LNC formulation was highly effective in the control of inflammation and could achieve these anti-inflammatory effects at doses $75 \%$ lower than conventional MTX administration in a dose-dependent manner. Moreover, it was effective on activated human synovial cells and in cellular conditions resistant to MTX. These findings demonstrate novel drug features of MTX administered as MTX-LNC that are of considerable biological and clinical interest in the treatment of RA and other autoimmune diseases. Further studies are necessary to understand the pharmacokinetics, pharmacodynamics, and toxicity at molecular levels, as well as to investigate the clinical efficacy of MTX-LNC. 


\section{Acknowledgments}

The authors would like to thank $\mathrm{CNPq} / \mathrm{Brasilia} / \mathrm{Brazil}$, CAPES, FAPERGS, Universal CNPq/MCTI-Brazil, PRONEX and PRONEM FAPERGS-CNPq, Rede nanobiotec-CAPES and INCT-CNPq/MCTI, and FAPEAM/AM for their financial support.

\section{Disclosure}

The authors declare no conflicts of interest in this work.

\section{References}

1. Tobon GJ, Youinou P, Saraux A. The environment, geo-epidemiology, and autoimmune disease: Rheumatoid arthritis. J Autoimmun. 2010; 35(1):10-14.

2. Kobelt G, Woronoff AS, Richard B, Peeters P, Sany J. Disease status, costs and quality of life of patients with rheumatoid arthritis in France the ECO-PR Study. Joint Bone Spine. 2008;75(4):408-415.

3. Dougados M, Soubrier M, Antunez A, et al. Prevalence of comorbidities in rheumatoid arthritis and evaluation of their monitoring: results of an international, cross-sectional study (COMORA). Ann Rheum Dis. 2014;73(1):62-68.

4. Gabriel SE, Crowson CS, Kremers HM, et al. Survival in rheumatoid arthritis: a population-based analysis of trends over 40 years. Arthritis Rheum. 2003;48(1):54-58.

5. McInnes IB, Schett G. The pathogenesis of rheumatoid arthritis. NEngl J Med. 2011;365(23):2205-2219.

6. Boechat Nde O, Ogusku MM, Boechat AL, Sadahiro A. Interaction between smoking and HLA-DRB1*04 gene is associated with a high cardiovascular risk in Brazilian Amazon patients with rheumatoid arthritis. PLoS One. 2012;7(8):e41588.

7. Kobelt G, Jönsson B. The burden of rheumatoid arthritis and access to treatment: outcome and cost-utility of treatments. Eur J Health Econ. 2008;8 Suppl 2:95-106.

8. Chan ES, Cronstein BN. Molecular action of methotrexate in inflammatory diseases. Arthritis Res. 2002;4(4):266-273.

9. Weinblatt ME, Coblyn JS, Fox DA, et al. Efficacy of low-dose methotrexate in rheumatoid arthritis. $N$ Engl J Med. 1985;312(13):818-822.

10. Chan ES, Cronstein BN. Molecular action of methotrexate in inflammatory diseases. Arthritis Res. 2002;4(4):266-273.

11. Chan ES, Cronstein BN. Methotrexate - how does it really work? Nat Rev Rheumatol. 2010;6(3):175-178.

12. Varatharajan N, Lim IG, Anandacoomarasamy A, et al. Methotrexate: long-term safety and efficacy in an Australian consultant rheumatology practice. Intern Med J. 2009;39(4):228-236.

13. Dervieux T, Furst D, Lein DO, et al. Polyglutamation of methotrexate with common polymorphisms in reduced folate carrier, aminoimidazole carboxamide ribonucleotide transformylase, and thymidylate synthase are associated with methotrexate effects in rheumatoid arthritis. Arthritis Rheum. 2004;50(9):2766-2774.

14. Wigginton SM, Chu BC, Weisman MH, Howell SB. Methotrexate pharmacokinetics after intraarticular injection in patients with rheumatoid arthritis. Arthritis Rheum. 1980;23(1):119-122.

15. Vanniasinghe AS, Bender V, Manolios N. The potential of liposomal drug delivery for the treatment of inflammatory arthritis. Semin Arthritis Rheum. 2009;39(3):182-196.

16. Bader RA. The development of targeted drug delivery systems for rheumatoid arthritis treatment. In: Lemmey $\mathrm{AB}$, editor. Rheumatoid Arthritis - Treatment. Rijeka and Shanghai: InTech; 2012:111-132. Available from: http://www.intechopen.com/books/rheumatoidarthritis-treatment/the-development-of-targeted-drug-delivery-systemsfor-rheumatoid-arthritis-treatment. Accessed July 22, 2015.

17. Barratt GM. Therapeutic applications of colloidal drug carriers. Pharm Sci Technolo Today. 2000;3(5):163-171.
18. Jäger E, Venturini CG, Poletto FS, et al. Sustained release from lipidcore nanocapsules by varying the core viscosity and the particle surface area. J Biomed Nanotechnol. 2009;5(1):130-140.

19. Venturini CG, Jäger E, Oliveira CP, et al. Formulation of lipid core nanocapsules. Colloids Surf A Physicochem Eng Asp. 2011;375(1-3): 200-208.

20. Fiel LA, Adorne MD, Guterres SS, Netz PA, Pohlmann AR. Variable temperature multiple light scattering analysis to determine the enthalpic term of a reversible agglomeration in submicrometric colloidal formulations: a quick quantitative comparison of the relative physical stability. Colloids Surf A Physicochem Eng Asp. 2013;431:93-104.

21. Poletto FS, Oliveira CP, Wender H, et al. How sorbitan monostearate can increase drug-loading capacity of lipid-core polymeric nanocapsules. J Nanosci Nanotechnol. 2015;15(1):827-837.

22. Poletto FS, Fiel LA, Lopes MV, et al. Fluorescent-labeled poly ( $\varepsilon$-caprolactone) lipid-core nanocapsules: synthesis, physicochemical properties and macrophage uptake. Journal of Colloid Science and Biotechnology. 2012;1(1):89-98.

23. Bernardi A, Frozza RL, Hoppe JB, et al. The antiproliferative effect of indomethacin-loaded lipid-core nanocapsules in glioma cells is mediated by cell cycle regulation, differentiation, and the inhibition of survival pathways. Int J Nanomedicine. 2013;8:711-728.

24. Schultze E, Ourique A, Yurgel VC, et al. Encapsulation in lipid-core nanocapsules overcomes lung cancer cell resistance to tretinoin. Eur J Pharm Biopharm. 2014;87(1):55-63.

25. Yurgel VC, Oliveira CP, Begnini KR, et al. Methotrexate diethyl esterloaded lipid-core nanocapsules in aqueous solution increased antineoplastic effects in resistant breast cancer cell line. Int J Nanomedicine. 2014;9:1583-1591.

26. Oliveira RT, Silva RM, Teo FH, et al. Detection of TCD4+ subsets in human carotid atheroma. Cytokine. 2013;62(1):131-140.

27. Sartori T, Seigi Murakami F, Pinheiro Cruz A, Machado de Campos A. Development and validation of a fast RP-HPLC method for determination of methotrexate entrapment efficiency in polymeric nanocapsules J Chromatogr Sci. 2008;46(6):505-509.

28. Pearson CM. Development of arthritis, periarthritis and periostitis in rats given adjuvants. Proc Soc Exp Biol Med. 1956;91(1):95-101.

29. Pissinate K, dos Santos Martins-Duarte É, Schaffazick SR, et al. Pyrimethamine-loaded lipid-core nanocapsules to improve drug efficacy for the treatment of toxoplasmosis. Parasitol Res. 2014;113(2): 555-564.

30. Dimer FA, Ortiz M, Pase CS, et al. Nanoencapsulation of olanzapine increases its efficacy in antipsychotic treatment and reduces adverse effects. J Biomed Nanotechnol. 2014;10(6):1137-1145.

31. Figueiró F, Bernardi A, Frozza RL, et al. Resveratrol-loaded lipid-core nanocapsules treatment reduces in vitro and in vivo glioma growth. J Biomed Nanotechnol. 2013;9(3):516-526.

32. Bulcão RP, Freitas FA, Venturini CG, et al. Acute and subchronic toxicity evaluation of poly( $\varepsilon$-caprolactone) lipid-core nanocapsules in rats. Toxicol Sci. 2013;132(1):162-176.

33. Bulcão RP, de Freitas FA, Dallegrave E, et al. In vivo toxicological evaluation of polymeric nanocapsules after intradermal administration. Eur J Pharm Biopharm. 2014;86(2):167-177.

34. Hegen M, Keith JC Jr, Collins M, Nickerson-Nutter CL. Utility of animal models for identification of potential therapeutics for rheumatoid arthritis. Ann Rheum Dis. 2008;67(11):1505-1515.

35. Mello SB, Tavares ER, Bulgarelli A, BonfáE, Maranhão RC. Intra-articular methotrexate associated to lipid nanoemulsions: anti-inflammatory effect upon antigen-induced arthritis. Int J Nanomedicine. 2013;8: $443-449$.

36. Williams AS, Camilleri JP, Goodfellow RM, Williams BD. A single intra-articular injection of liposomally conjugated methotrexate suppresses joint inflammation in rat antigen-induced arthritis. $\mathrm{Br} J$ Rheumatol. 1996;35(8):719-724.

37. Prabhu P, Shetty R, Koland M, et al. Investigation of nano lipid vesicles of methotrexate for anti-rheumatoid activity. Int J Nanomedicine. 2012; 7:177-186. 
38. Nam JL, Ramiro S, Gaujoux-Viala C, et al. Efficacy of biological diseasemodifying antirheumatic drugs: a systematic literature review informing the 2013 update of the EULAR recommendations for the management of rheumatoid arthritis. Ann Rheum Dis. 2014;73(3):516-528.

39. Smolen JS, Aletaha D, Bijlsma JW, et al; T2T Expert Committee. Treating rheumatoid arthritis to target: recommendations of an international task force. Ann Rheum Dis. 2010;69(4):631-637.

40. Firestein GS. Evolving concepts of rheumatoid arthritis. Nature. 2003; 423(6937):356-361.

41. Taylor PC, Mehta P, Tull T. Aetiopathology of rheumatoid arthritis. Medicine. 2010;38(4):163-166.

42. Bernardi A, Frozza RL, Hoppe JB, et al. The antiproliferative effect of indomethacin-loaded lipid-core nanocapsules in glioma cells is mediated by cell cycle regulation, differentiation, and the inhibition of survival pathways. Int J Nanomedicine. 2013;8:711-728.
43. Bernardi A, Zilberstein A, Jäger E, et al. Effects of indomethacin-loaded nanocapsules in experimental models of inflammation in rats. $\mathrm{Br} J$ Pharmacol. 2009;158(4):1104-1111.

44. Zhao R, Goldman ID. Resistance to antifolates. Oncogene. 2003;22(47): 7431-7457.

45. Banerjee D, Mayer-Kuckuk P, Capiaux G, Budak-Alpdogan T, Gorlick R, Bertino JR. Novel aspects of resistance to drugs targeted to dihydrofolate reductase and thymidylate synthase. Biochim Biophys Acta. 2002;1587(2-3):164-173.

46. Noé V, Alemany C, Nicolás M, Ciudad CJ. Sp1 involvement in the 4beta-phorbol 12-myristate 13-acetate (TPA)-mediated increase in resistance to methotrexate in Chinese hamster ovary cells. Eur J Biochem. 2001;268(11):3163-3173.

\section{Publish your work in this journal}

The International Journal of Nanomedicine is an international, peerreviewed journal focusing on the application of nanotechnology in diagnostics, therapeutics, and drug delivery systems throughout the biomedical field. This journal is indexed on PubMed Central, MedLine, CAS, SciSearch ${ }^{\circledR}$, Current Contents ${ }^{\circledR} /$ Clinical Medicine,
Journal Citation Reports/Science Edition, EMBase, Scopus and the Elsevier Bibliographic databases. The manuscript management system is completely online and includes a very quick and fair peer-review system, which is all easy to use. Visit http://www.dovepress.com/ testimonials.php to read real quotes from published authors. 